Pyrohov T., Korolev A.

\title{
DETERMINING THE DISTRIBUTION OF TEMPERATURE FIELDS IN CONSTRUCTION ELEMENTS OF SHELL-AND-TUBE HEAT EXCHANGERS USING ANALYTICAL AND NUMERICAL HEAT AND HYDRAULIC CALCULATIONS
}

The object of research is numerous and analytical thermohydraulic calculations of a shell-and-tube heat exchanger of a counterflow type. To determine the thermally stressed state of heat exchangers, calculations of the temperature fields of their elements are performed. At the same time, it is not a trivial task to perform numerical thermohydraulic calculations for a heat exchanger that has a large number of heat exchange tubes. This statement is due to the fact that the calculation model will contain a large number of finite elements. Difficulties in performing these calculations may arise when using electronic computers with limited technical parameters. Such calculations may take quite a long time, or may not be performed at all.

The authors proposed an approach to determining the temperature fields in individual elements of a heat exchanger. It consists of a combination of analytical and numerical thermohydraulic calculations of individual elements of the heat exchanger and the internal bodies in contact with them. This allows to reduce the time and bit depth of calculations.

To validate the above-mentioned approach, two calculation models of a shell-and-tube heat exchanger of a counterflow type were built. As the first calculation model, the entire body of the heat exchanger was constructed, taking into account the bodies of its coolant and cooling water. For this model, only numerical thermohydraulic calculations were performed. As the second calculation model, a part of the heat exchanger was built, taking into account all the bodies of the coolant and cooling water, belonging to it. With the help of analytical thermal calculations, the temperatures at the inlet to the shell-and-tube spaces of the second design model were determined. Subsequently, the results obtained analytically served as boundary conditions for performing numerical thermohydraulic calculations.

As a result of the calculations performed, a comparison of the obtained results of the distribution of temperature fields in the above-mentioned calculation models is made. Based on the analysis of the results, it was concluded that it is possible to use a combined method (a combination of analytical and numerical thermohydraulic calculations) for determining the temperature fields in individual elements of heat exchangers.

Keywords: shell-and-tube heat exchanger, thermal-hydraulic calculations, thermo-stress-strain state, temperature field calculation, finite elements.

\section{Introduction}

Analysis of approaches to performing numerical thermohydraulic calculations shows that most research and analytical work is based on the analysis of primitive calculation models, for example [1-3]. This is justified by the fact that the performance of numerical thermohydraulic calculations of a heat exchangers, which have a large number of heat exchange tubes, requires the use of a significant number of finite elements for constructing the internal bodies, as well as its body elements. Difficulties in performing these calculations may arise when using electronic computers with limited technical capabilities. Such calculations may take quite a long time, or may not be executed at all.
At the same time, in some analytical works, studies are being carried out to optimize the performance of thermohydraulic calculations, an example of such studies can be cited in $[4,5]$.

It should be noted that numerical hydraulic calculations can only be an intermediate stage, for example, when determining the thermally stressed state of heat exchanger elements. In cases where it is necessary to determine the thermally stressed state of individual elements of shell-andtube heat exchangers, the authors propose not to perform thermohydraulic calculations of the entire heat exchanger model, but only in its individual elements, using a combination of analytical and numerical thermal calculations. This will reduce the time and bit depth of calculations. 
In this regard, the object of this research is the numerical and analytical thermohydraulic calculations of a shelland-tube heat exchanger of a counterflow type. The aim of this research is to substantiate the possibility of using a combined method for determining temperature fields in heat exchangers, obtained by combining analytical thermal calculations and calculations by the finite element method (FEM).

\section{Methods of research}

2.1. Description of the research object. Let's consider a shell-and-tube heat exchanger of a counterflow type, the general view of which is shown in Fig. 1.

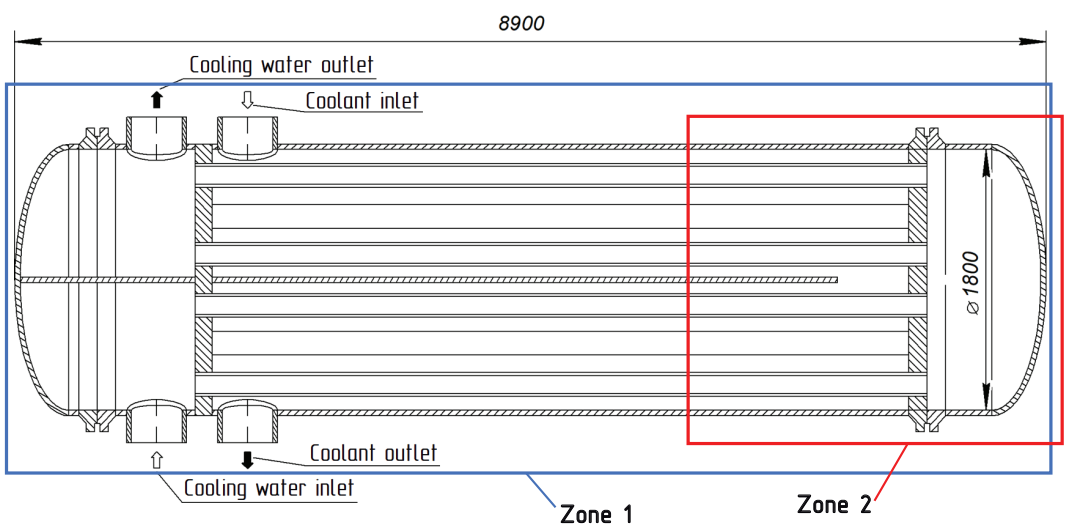

Fig. 1. General view of a shell-and-tube heat exchanger of counterflow type

To solve this research aim, two calculation models have been developed:

- the first design model, which includes all elements

of the heat exchanger (Zone 1, Fig. 1);

- the second calculation model, which includes only

Zone 2 of the heat exchanger (Fig. 1).

The temperature of the cooling water, that enters the tube space, at the inlet to the heat exchanger is $5^{\circ} \mathrm{C}$. The temperature of the coolant, that enters the shell side of the heat exchanger, changes at the inlet from $+60{ }^{\circ} \mathrm{C}$ to $+150{ }^{\circ} \mathrm{C}$, in accordance with the graph of the temperature variation with time, which is shown in Fig. 2.

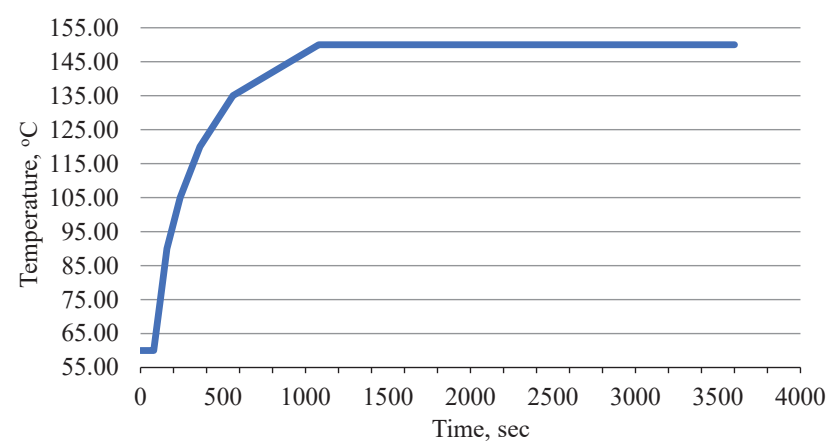

Fig. 2. Coolant temperature variation with time

The value of the pressure of the coolant and cooling water is constant and equal to 2.1 and $0.5 \mathrm{MPa}$, respectively. Similarly, the mass flow rates for the coolant and cooling water are equal to $700 \mathrm{t} / \mathrm{h}$ and $150 \mathrm{t} / \mathrm{h}$. Water is taken as the coolant and cooling water, and structural steel is used as the material of the heat exchanger elements.
2.2. Description of the mathematical model of numerical thermohydraulic calculations. To solve the problem posed to determine the distribution of temperature fields in the elements of the heat exchanger, numerical thermohydraulic calculations performed using the FEM method [6] were used. To perform such calculations, a mathematical model of fluid flow was used, which is based on the Reynoldsaveraged Navier-Stokes equations for an incompressible fluid. They are represented by the equations of continuity, change in momentum and conservation of energy.

Proceeding from the fact that the fluids in the heat exchanger move turbulently, to simulate the effect of turbulence and describe the turbulent boundary layer on solid surfaces, Menter's $k-\omega$ model is adopted as a temporal model $[7,8]$. This model provides sufficient accuracy of the results and effective convergence of the iterative process even with rather coarse grids and with a moderate bit depth of the limiting layer [9].

Heat transfer in the housing is modeled by the heat conduction equation:

$$
\frac{d}{d t}\left(\rho c_{p} T\right)=\frac{d}{d x_{j}}\left(\lambda \frac{d T}{d x_{j}}\right)+q_{v}
$$

where $t$ - time; $x_{j}$ - Cartesian coordinates; $\rho$ - density; $c_{p}$ - heat capacity at constant pressure; $T$ - temperature; $\lambda$ - thermal conductivity, $q_{v}$ - heat flux.

The boundary conditions for performing numerical thermohydraulic calculations are the mass flow rate, pressure and temperature of the liquid at the inlet to the shell-andtube spaces. It was assumed that from the outside the heat exchanger does not have thermal insulation and is blown by air with a temperature of $20^{\circ} \mathrm{C}$ and natural convection.

To solve the general problem of thermal hydraulics and thermal conductivity, on the boundary between the liquid and the elements of the heat exchanger body, the equality of temperatures and heat fluxes is taken.

2.3. Description of the first calculation model. As the first calculation model, the entire body of the heat exchanger was constructed, taking into account the bodies of the coolant and cooling water. The general view of the first finite element calculation model of the heat exchanger is shown in Fig. 3. This model includes 3,269,908 nodes and 4,421,121 finite elements, and takes into account five cells in the boundary layer of the fluid.

2.4. Description of the second calculation model. As the second calculation model, a part of the heat exchanger was built. Ehe general view of the finite element calculation model of the heat exchanger, coolant and cooling water is shown in Fig. 4. This model includes 984,912 nodes and 1,332,479 finite elements, and takes into account five cells in the boundary layer of liquids. Analytical thermal calculations were performed to determine the temperatures at the inlet to the shell-andtube spaces of the second design model. With the help of these calculations, the average value of the temperature of the coolant and cooling water in a given section of the heat exchanger is determined. In the future, the results obtained analytically serve as boundary conditions for performing numerical thermohydraulic calculations by the FEM method. 


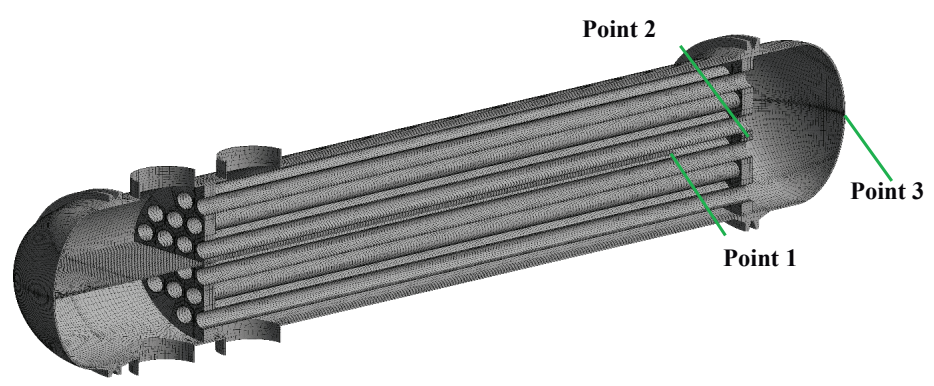

$a$

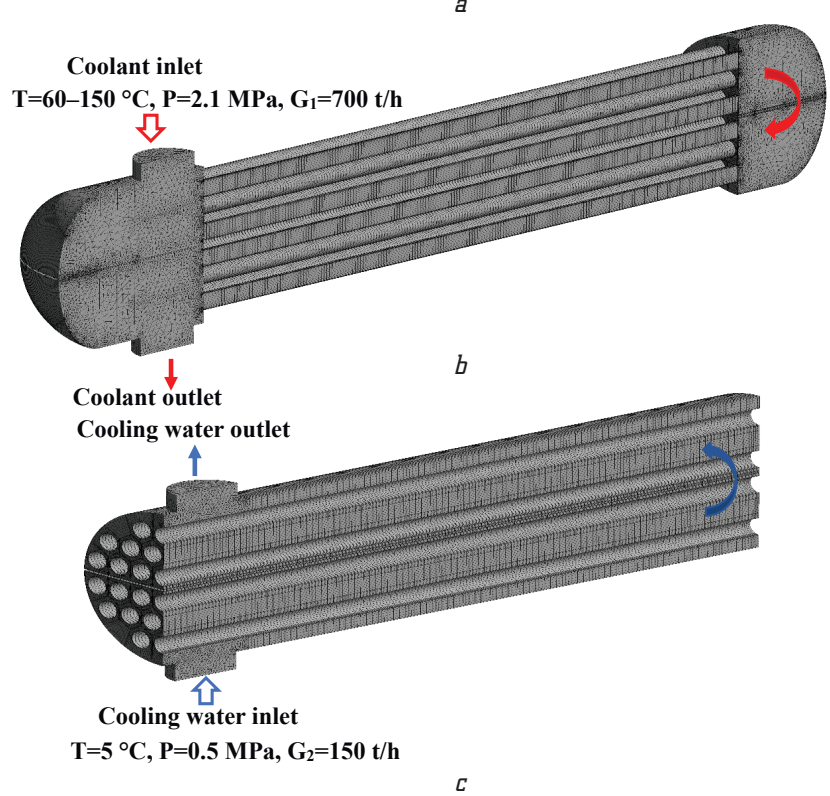

Fig. 3. General view of the finite element calculation model of the heat exchanger: $a$ - body; $b$ - cooling water; $c$ - coolant

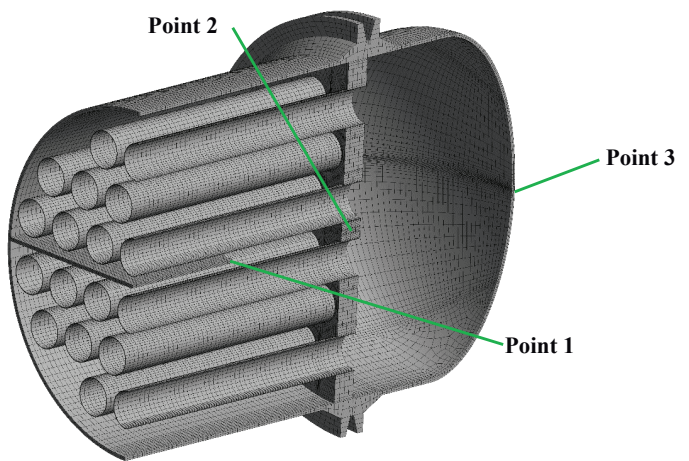

$a$

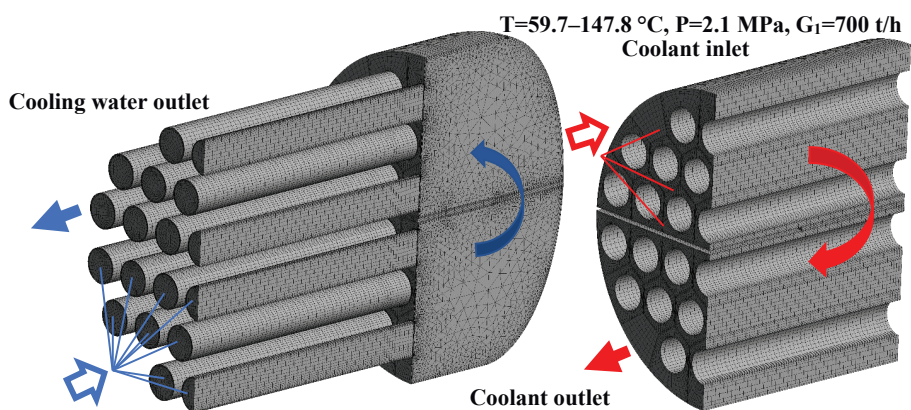

Cooling water inlet

$\mathrm{T}=5.8-7.0{ }^{\circ} \mathrm{C}, \mathrm{P}=0.5 \mathrm{MPa}, \mathrm{G}_{2}=150 \mathrm{t} / \mathrm{h}$

$b$

C

Fig. 4. General view of the finite element calculation model of separate part of the heat exchanger: $a$ - body; $b$ - cooling water; $c$ - coolant
Let's formulate a mathematical model of analytical thermal calculation to determine temperatures over the cross-section of shell-and-tube heat exchangers of the counterflow type $[10,11]$.

The formula for the temperature difference, changing along the length of the heat exchanger, in accordance with:

$$
\Delta t=\Delta t_{0} e^{-m k F},
$$

where $\Delta t=t_{2}-t_{1}$ - temperature difference between the coolant and cooling water of the heat exchanger, at one point of its length, ${ }^{\circ} \mathrm{C} ; \Delta t_{0}-$ temperature difference at the end of the heat exchanger, ${ }^{\circ} \mathrm{C}$ :

$$
\Delta t_{0}=t_{2}^{\prime \prime}-t_{1}^{\prime}
$$

where $t_{1}^{\prime}$ - initial temperature of the cooling water, ${ }^{\circ} \mathrm{C} ; t_{2}^{\prime \prime}$ - final temperature of the coolant, ${ }^{\circ} \mathrm{C}$; $k$ - heat transfer coefficient; $F$ - heat exchange surface area, $\mathrm{m}^{2} ; m-$ constant, c.deg/J:

$$
m=\frac{1}{G_{1} c p_{1}}-\frac{1}{G_{2} c p_{2}},
$$

where $G_{1}, G_{2}$ - mass volume of liquids, $\mathrm{kg} / \mathrm{s} ; c p_{1}$, $c p_{2}$ - specific heat capacities of liquids, $\mathrm{J} /(\mathrm{kg} \cdot \mathrm{deg})$.

Let's use the formula for the heat balance of the heat exchanger:

$$
Q=G_{1} c p_{1}\left(t_{1}^{\prime \prime}-t_{1}^{\prime}\right)=G_{2} c p_{2}\left(t_{2}^{\prime}-t_{2}^{\prime \prime}\right),
$$

where $t_{2}^{\prime}$ - initial temperature of the coolant, ${ }^{\circ} \mathrm{C}$; $t_{1}^{\prime \prime}$ - final temperature of the cooling water, ${ }^{\circ} \mathrm{C}$.

From formula (2), it is possible to determine the temperature value over the cross section of the heat exchanger, at given points of the length of its heat exchange elements:

$$
\begin{aligned}
& t_{1}=t_{1}^{\prime}+\frac{G_{2} c p_{2}}{G_{1} c p_{1}}\left(t_{2}-t_{2}^{\prime \prime}\right), \\
& t_{2}=\frac{t_{1}^{\prime}-\frac{G_{2} c p_{2}}{G_{1} c p_{1}} t_{2}^{\prime \prime}+\left(t_{2}^{\prime \prime}-t_{1}^{\prime}\right) e^{-m k F}}{1-\frac{G_{2} c p_{2}}{G_{1} c p_{1}}},
\end{aligned}
$$

where, $t_{1}$ - cooler temperature, at a given point of the heat exchanger length, ${ }^{\circ} \mathrm{C} ; t_{2}-$ coolant temperature, at a given point of the heat exchanger length, ${ }^{\circ} \mathrm{C}$.

\section{Research results and discussion}

3.1. Results of numerical thermohydraulic calculations of the first computational model. As a result of the performed numerical thermohydraulic calculations using the FEM method, the distribution of temperature fields over the thickness and length of the walls of the heat exchanger elements was obtained.

A graphical view of the distribution of the temperature fields obtained for the calculation execution time of $1 \mathrm{~s}$ and $3600 \mathrm{~s}$ is shown in Fig. 5. 

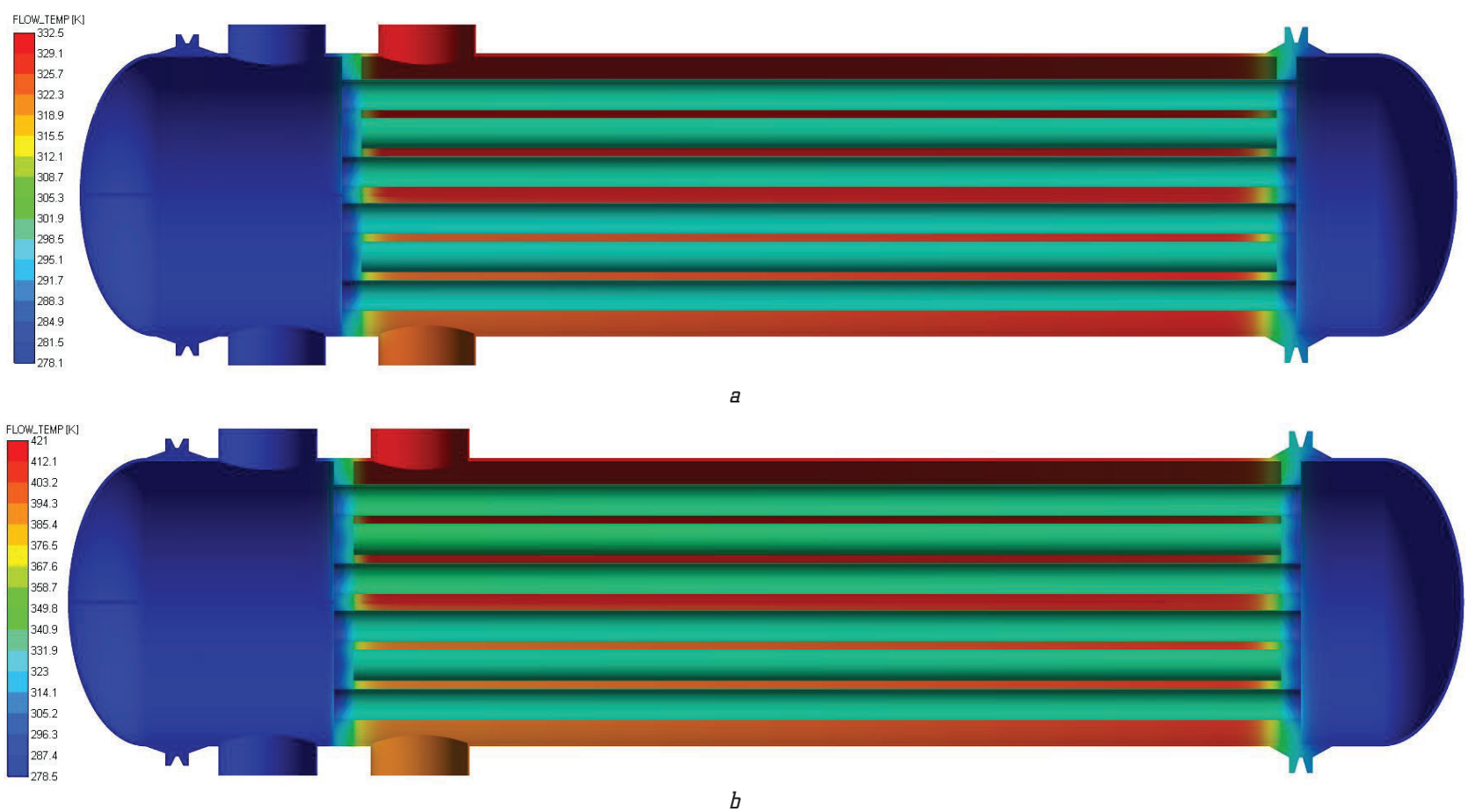

Fig. 5. Distribution of temperature fields in the elements of the first calculation model of the heat exchanger for: $a-1$ second; $b-3600$ second from the calculation

3.2. Results of numerical thermohydraulic calculations of the second computational model. With the help of analytical calculations performed using equations (2)-(5), it was determined that the temperature value at the inlet of the coolant into the shell of the second design model changes from $59.7{ }^{\circ} \mathrm{C}$ to $147.8^{\circ} \mathrm{C}$. Cooling water change from $5.8{ }^{\circ} \mathrm{C}$ to $7.0{ }^{\circ} \mathrm{C}$. These temperature values served as boundary conditions for the numerical thermohydraulic calculation of the second calculation model performed using the FEM method.

A graphical view of the distribution of temperature fields in the elements of the second calculation model, obtained for a computation time of 1 second and 3600 second, is shown in Fig. 6.

3.3. Comparison of the obtained results. Compare the values of the obtained temperatures of the coolant over

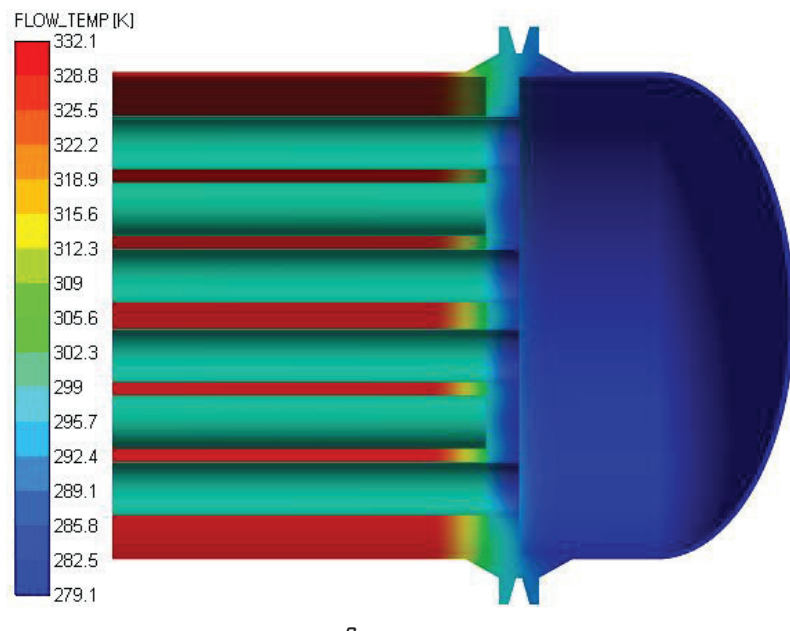

the cross section of the heat exchanger, obtained analytically for the second calculation model, and as a result of the numerical thermohydraulic calculation of the first calculation model. The graphs of temperature changes over time are shown in Fig. 7.

As seen in the graph in Fig. 7, the difference in temperatures obtained by analytical and numerical calculations does not exceed $4 \%$. This indicates the sufficient accuracy of analytical thermal calculations and the possibility of their application to determine the boundary conditions for numerical thermohydraulic calculations.

Compare the values of the obtained temperature variation in the elements of the calculation models, with time. For this, let's compare three similar points in the first and second calculation models of the heat exchanger. Graphs of temperature variation with time, at the indicated points of the heat exchanger elements are shown in Fig. 8-10.

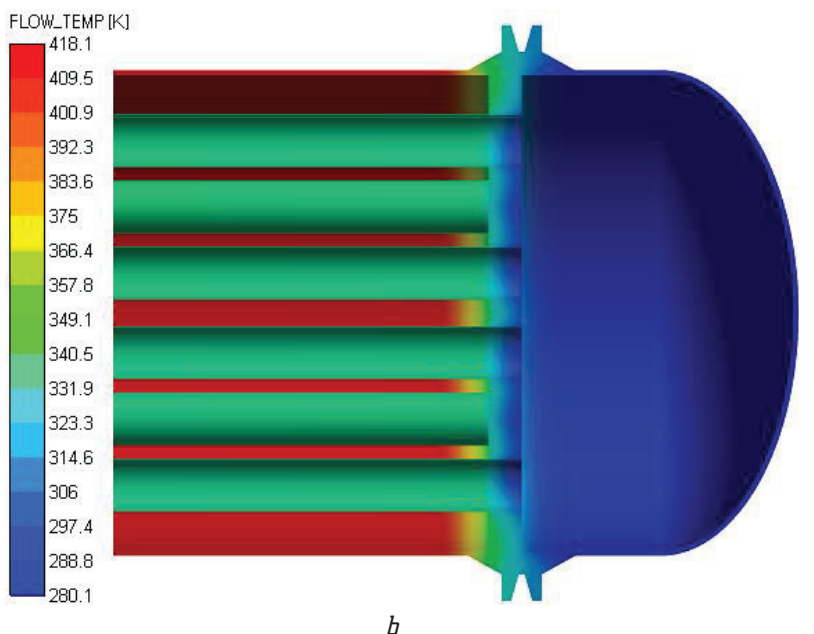

Fig. 6. Distribution of temperature fields in the elements of the second calculation model of the heat exchanger for: $a-1$ second; $b-3600$ second 


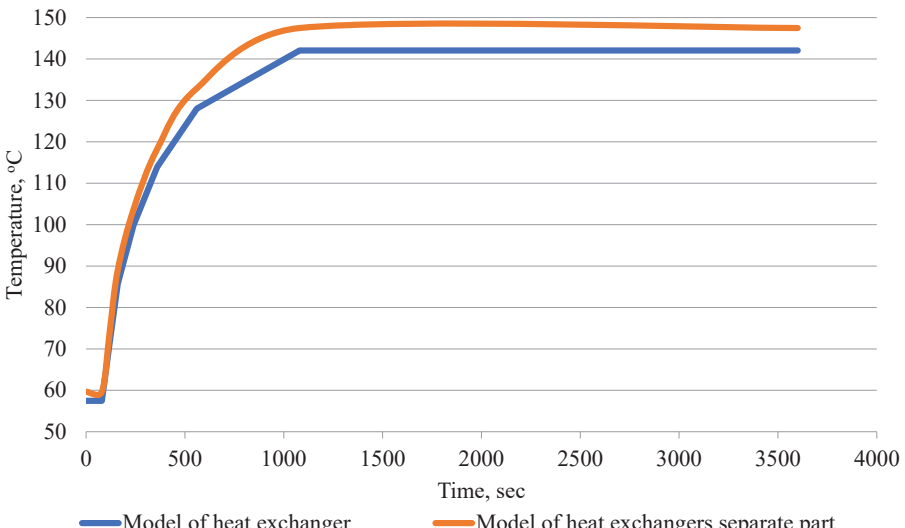

Fig. 7. Distribution of the obtained temperatures of the coolant over the cross section of the heat exchanger, with time

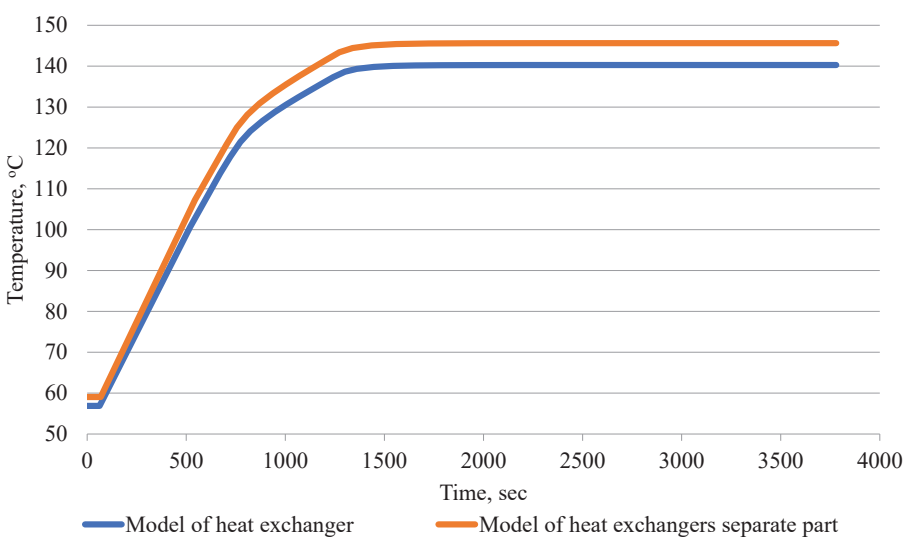

Fig. 8. Distribution of temperature variation with time at point

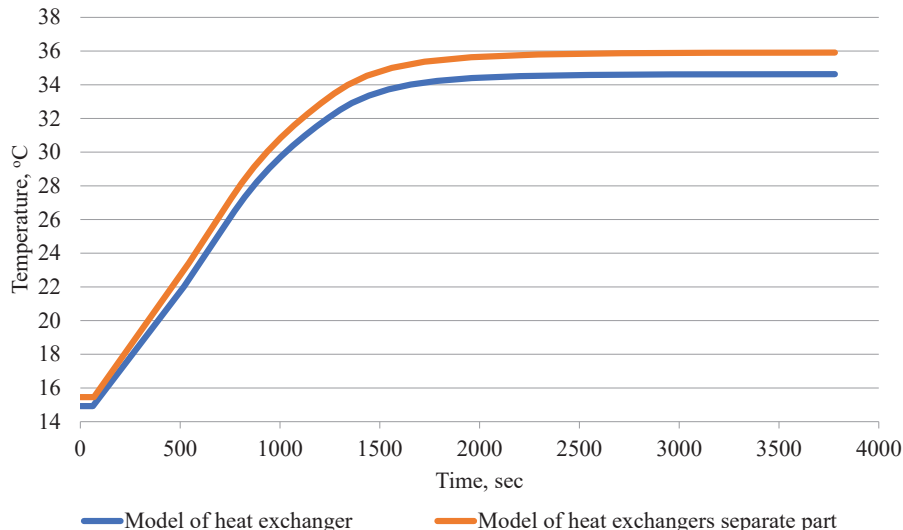

Fig. 9. Distribution of temperature variation with time at point 2

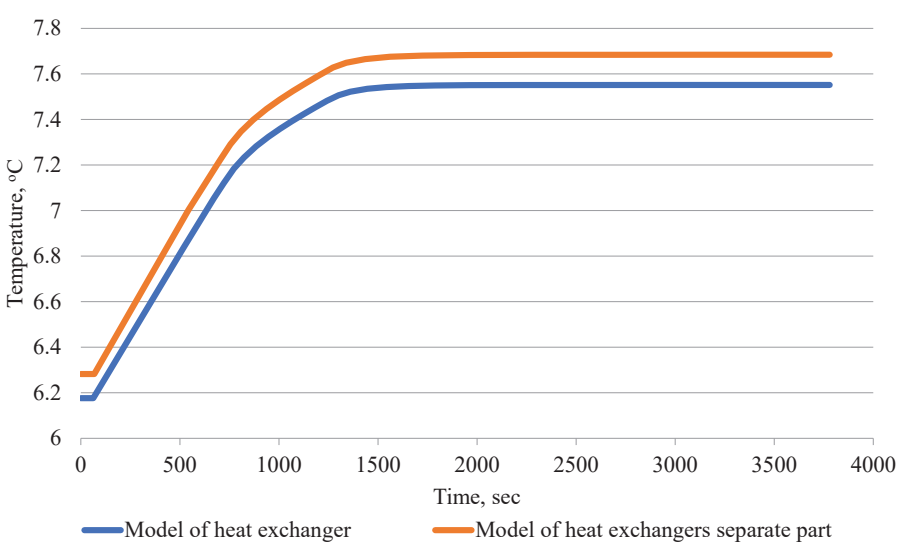

Fig. 10. Distribution of temperature variation with time at point 3
An analysis of the obtained results showed that the difference in temperature values at similar points of the first and second calculation models does not exceed $3.8 \%$. That is, it can be argued about the high accuracy of the results obtained by using the approach proposed by the authors to determine the temperature fields in shell-and-tube heat exchangers. At the same time, the dimension of the problem and calculations decreased by 3.32 times (from 4,420,000 finite elements for a complete model of a heat exchanger to 1,330,000 finite elements for a model of its separate part).

\section{Conclusions}

In this article, the authors provide an approach to determining the temperature fields in shell-and-tube heat exchangers using a set of analytical calculations and calculations by the FEM method. Additionally, a detailed comparison of the results of thermal calculations performed using the proposed approach and the classical method of calculating the entire heat exchanger is performed.

Based on the results of the analysis of the obtained calculation results, the following conclusions can be drawn:

1) the values of the temperatures of the coolant and cooling water over the cross section of the heat exchanger, obtained using analytical thermal calculations, show the possibility of using these results as boundary conditions for subsequent numerical thermohydraulic calculations;

2) the difference between the calculation results obtained using only numerous thermohydraulic calculations by the FEM method, as well as the results of a set of analytical calculations and numerous thermohydraulic calculations by the FEM method, for the considered calculation models does not exceed $3.8 \%$;

3 ) the dimension of the calculation model has decreased by 3.32 times, the time for performing calculations has decreased in the same way.

As a research result, it can be concluded that to determine the temperature fields in individual elements of heat exchangers, there is no need to perform calculations of all its elements, it is enough to determine the boundary conditions for the necessary part of it, which should include the objects of research. This approach allows to reduce the number of finite elements and the time for performing calculations, and also allows to get fairly accurate results.

\section{References}

1. Renze, P., Akermann, K. (2019). Simulation of Conjugate Heat Transfer in Thermal Processes with Open Source CFD. ChemEngineering, 3 (2), 59. doi: http:// doi.org/10.3390/chemengineering3020059

2. Abbasian Arani, A. A., Uosofvand, H. (2019). Improving shell and tube heat exchanger thermohydraulic performance using combined baffle. International Journal of Numerical Methods for Heat \& Fluid Flow, 30 (8), 4119-4140. doi: http://doi.org/10.1108/hff-062019-0514

3. Hemanth, M., Mulabagal, S. (2017). CFD analysis of shell and tube heat exchanger with and without baffles by using nano fluids. International Journal of Emerging Technologies and Innovative Research, 4 (12), 25-31. 
4. Petrik, M., Szepesi, G. L. (2018). Shell Side CFD Analysis of a Model Shell-and-Tube Heat Exchanger. Chemical engineering transactions, 70, 313-318. doi: http://doi.org/10.3303/ CET1870053

5. Heat Transfer Optimization of Shell-and-Tube Heat Exchanger through CFD Studies (2011). Goteborg: Chalmers University of Technology, 39

6. Zenkevich, O. (1975). The finite element method in technology. Moscow: Mir Publishing House, 541.

7. Menter, F. R. (1997). Eddy Viscosity Transport Equations and Their Relation to the $k-\varepsilon$ Model. Journal of Fluids Engineering, 119 (4), 876-884. doi: http://doi.org/10.1115/1.2819511

8. Menter, F. R. (1994). Two-equation eddy-viscosity turbulence models for engineering applications. AIAA Journal, 32 (8), 1598-1605. doi: http://doi.org/10.2514/3.12149

9. Belov, I. A. (2001). Modeling turbulent flows. Saint Petersburg: BSTU, 107.
10. Florea, O., Smigelsky, O.; Kagan, S. Z. (Ed.) (1971). Calculations for processes and devices of chemical technology. Moscow: Chemistry, 448

11. Kern D. (1950). Process Heat Transfer. McGraw-Hill, 871

Pyrohov Tymofii, Head of Department, Division of Strength Analysis of Elements of Nuclear Installations, State Enterprise «State Scientific Engineering Center of Control Systems and Emergency Response», Kyiv, Ukraine, e-mail:T.V.Pirogov@gmail.com,ORCID: http://orcid.org/ 0000-0002-0877-1251

Korolev Alexander, Doctor of Technical Sciences, Professor, Department of Nuclear Power Plants, Odessa National Polytechnic University, Odessa, Ukraine, e-mail: Korolyov118@gmail.com, ORCID: http:// orcid.org/0000-0002-7898-8659

Liashenko $\mathbf{A}$.

INVESTIGATION OF HYDROCARBON
SOLVENTS FOR THE CONTROL OF
PARAPHYN-HYDRATE DEPOSITS
IN OIL WELLS

The object of research is hydrocarbon solvents for the elimination of paraffin-hydrate deposits. The chemical methods of control of paraffin-hydrate deposits, in particular, application of hydrocarbon solvents are considered in the article. Studies of the effect of various chemical reagents on the dissolution of hydrate formations using a laboratory installation at different thermo-baric regimes, closest to the real conditions of the pipe space of oil and gas wells: the temperature varied discretely from -10 to $+40{ }^{\circ} \mathrm{C}$ and pressure from 0 to $10 \mathrm{MPa}$. To study the effect of hydrocarbon solvents on the process of removing hydrate formations, the most rational methods of regression analysis and mathematical planning of the experiment were used - simplex-grid planning. The $G$-criterion of plan optimality was used, which includes 22 experiments. The synthesis of the plan was implemented by numerical methods on a software-controlled device for information processing. The use of such methods makes it possible to reasonably organize experimental research, adjust the time, equipment, materials and perform the required number of experiments. The results of measurements are shown in the diagrams for each solvent separately. The obtained data allowed to a priori substantiate the choice of the optimal variant of application of chemical reagents for complete dissolution and removal of paraffin-hydrate formations from the surface of the internal well equipment. Analysis of the data shows that the solubility reagents butyl cellosolve and ethylacetat solvents, which can be recommended for wide application in the oil and gas industry, are characterized by the highest solubility and efficiency for removal of paraffin-hydrate deposits from the surface of well equipment. An important fact is that the consumption of the proposed solvents per one well operation is not more than $4 \mathrm{~m}^{3}$, which is $2-3$ times less than in other known analogues. The use of new solvents also allows to increase the inter-cleaning period of the well more than 2-3 times, which reduces the cost of extracted products.

Keywords: paraffin-hydrate deposits, hydrocarbon solvent, internal well equipment, chemical reagent, well cleaning interval.

\section{Introduction}

Resins, asphaltenes and paraffins are deposited on the surface of downhole equipment (casings and compressor pipes, pump housings, pump rods) along with hydrate formations.
It is necessary to use a multipurpose reagent for dissolving and removing all types of such deposits at the same time. Laboratory tests were performed to select such a chemical reagent.

The analysis of scientific literature sources showed there is a problem of precipitation of paraffin-hydrates in the process 